\title{
Focus on Clinical Practice: Improving the Quality of Care
}

\author{
Marjorie A. Bowman, MD, MPA, and Anne Victoria Neale, PhD, MPH
}

In this diverse issue, we have a report on the high cost of diabetes quality improvement programs. Two studies using health information technology, including one that embedded a questionnaire and tool for bipolar disorder into an electronic health record to improve diagnosis, and another that collected information about anxiety and depression for adolescents with a personal digital assistant. Other articles considered sources of disparities in screening for colorectal cancer in rural Georgia, and the characteristics of sepsis in HIV patients. Clinicians will likely find interesting how patients interpret and report provider reactions to interpersonal violence situations. We also have a review of the symptoms patients report in a community practice sample; breast cancer survivors' perspectives on acupuncture for treating hot flashes; clinical reviews about Alzheimer disease and prasugrel; and several interesting brief case reports. (J Am Board Fam Med 2012;25:263-265.)

The care of patients with diabetes is significantly more expensive than most other patients. Now, West ${ }^{1}$ finds that the dollar cost for diabetes quality improvement (QI) programs is substantial. Given that it is one of the top 3 medical diagnoses in my (MAB) office, and probably in many offices, undertaking QI programs such as this can result in large and unreimbursed expenses. One of my (MAB) local insurers pays $\$ 3.00$ per member per month (PMPM) for a level III medical home. In the meantime, this article shows that the cost of implementing the diabetes QI program was \$6.23 PMPM and maintenance of the program was $\$ 3.83$ PMPM, and this is just the QI portion of the program specific to diabetes, not the extra visits, extra phone calls, or extra time per visit for the patients with diabetes. Insurers and institutions must understand and cover these costs. We are hopeful that these programs save other costs outside of our offices by reducing hospitalizations and emergency department visits.

Gill et $\mathrm{al}^{2}$ embedded a tool to diagnose bipolar disorder in the Centricity electronic medical record (GE Healthcare, Princeton Township, NJ), used by a group of practices across the United States, and reported an association with an increased rate of

Funding: none.

Conflict of interest: The authors are editors of the JABFM. both diagnosis of bipolar disorder (BPD) and medical treatment. The BPD screening tool automatically presented when a patient with a previous diagnosis of depression was seen, and clinicians could click through to various resources about the disease. although some patients who were low risk on the screening instrument received the diagnosis of BPD-perhaps false positives-more in the intervention practices and with higher scores were diagnosed (more likely appropriately so). Of note, the practices were not randomized because the offices had the option to participate or not participate in the study of BPD; this is a common methodologic challenge for research conducted in the real world of the primary care clinical practice setting.

Olson et $\mathrm{al}^{3}$ successfully used a personal digital assistant (PDA) with adolescents to explore their symptoms of anxiety and depression and the factors correlated with these symptoms. Stress, substance abuse, and anger all were associated with both anxiety and depressive symptoms. Thankfully, those adolescents who reported they had parents who listened had less depression and anxiety. How to create the circumstances and behaviors that help adolescents feel heard is neither clear nor simple.

In a study of symptoms reported in routine practice, South-Paul et $\mathrm{al}^{4}$ found current anxiety and depression symptoms were common. It is interesting that leg symptoms were more common among 
African Americans and headaches were more common among whites. Depression symptoms were highly associated with reported anxiety and a family history of depression.

Wilkins et $\mathrm{al}^{5}$ report that, in 2 rural Georgia counties, the rate of colonoscopy for black respondents was $20 \%$ lower than the rate for white respondents. African Americans noted many more barriers to and perceived less benefit from screening. Those who were not currently screened were much less likely to be insured or to have a personal physician and had less education. Overall, physician recommendation was more important than patient race in determining the likelihood that a patient had received screening for colorectal cancer, a result that was self-reported by screened patients. Interventions to improve physician recommendations as well as to encourage patients to ask their doctors about colorectal cancer (thus prompting physician recommendation and orders) thus seem to be an important intervention for these rural counties, but providing access to insurance and a personal physician may be key.

There is not much literature about sepsis in individuals with HIV. In clinical observation research, Haddy et $\mathrm{al}^{6}$ reviewed charts of 83 patients with HIV and sepsis (including bacteremia or fungemia). Their helpful findings included that (1) more than one third did not have a fever; (2) more than half had no apparent source of fever; (3) there was a large range of organisms involved (the most common were methicillin-sensitive Staphylococcus aureus and Mycobacterium avian complex, yet these 2 accounted for fewer than half of the bacterial isolates); (4) $14 \%$ had polymicrobial sepsis; and (5) $12 \%$ died.

Hot flashes are particularly problematic for breast cancer survivors because common treatments induce this uncomfortable, frequent, and disruptive symptom. Mao et $\mathrm{al}^{7}$ explored the beliefs about acupuncture for this group of women. Acupuncture appealed to many breast cancer survivors because it is considered to be "natural" and is not expected to have many side effects.

Interpersonal violence (IPV) is common and complex enough that interacting with and supporting patients involved with IPV in primary care practice is an demanding matter. The article by Morse et $\mathrm{al}^{8}$ about women who have experienced IPV reporting their interactions with health care providers includes some reassuring notes: women most often told their primary care physician rather than other health care providers, and those who did found their physicians open to discussing this problem. However, most would not have reported it unless asked, and many women also reported they did not receive information about safety. It is important to note that these findings are as reported by the women (self-report), not through asking the physician or checking records. Nevertheless, either these women did not receive information about safety or they did not hear it in a manner that they could understand. Thus, we need to provide information about safety and have the patient repeat back what they heard to ensure understanding. Providing patient handouts or brochures and referrals to community services also can reinforce the message.

We have 3 clinical reviews this month. Koshy ${ }^{10}$ provides an update on the data behind the recommended use of prasugrel. Sadowsky ${ }^{11}$ and Galvin ${ }^{12}$ provide a wealth of information about Alzheimer disease in 2 articles: one that highlights some practical tools for screening and diagnosis and one that provides a practical, evidence-based review of the treatment of $\mathrm{AD}$. We have come so far in understanding nonpharmacologic treatments over the last 25 years. Many of the nonpharmacologic hints are useful for various types of dementias and are practical and useful for caregivers. For some caregivers, this article would be an excellent handout.

Lee and Cheong, ${ }^{13} 2$ family physicians from Korea, provide an interesting report of their endoscopic repair of a perforation that occurred during a routine screening colonoscopy. Mounsey et al, ${ }^{14}$ family physicians from the United States, discuss a case of strongyloides causing a fever of unknown origin in an immunocompetent man, reviewing both the common and uncommon forms (such as this one) of helminth infection. Brown et $\mathrm{a}^{15}$ found that drug samples in the office are often expired! Finally, Pavletic et $\mathrm{al}^{16}$ discuss respiratory muscle insufficiency as a cause of dyspnea.

\section{Editorial Office News and Notes}

Content usage in 2011 was at an all-time high and reached an all-time high of 2.89 million requests. Be sure to see our top-read articles among those published in 2011! 


\section{References}

1. West DR, Radcliff TA, Brown T, Cote MJ, Smith PC, Dickinson WP. Costs associated with data collection and reporting for diabetes quality improvement in primary care practices: a report from SNOCAP-USA. J Am Board Fam Med 2012;25: 275-282.

2. Gill JM, Chen YX, Grimes A, Klinkman MS. Using electronic health record-based tools to screen for bipolar disorder in primary care patients with depression. J Am Board Fam Med 2012;25:283-290.

3. Dumont IP, Olson AL. Primary care, depression, and anxiety: exploring somatic and emotional predictors of mental health status in adolescents. J Am Board Fam Med 2012;25:291-299.

4. Janosky JE, South-Paul JE, Lin CJ. Pain and depression in a cohort of underserved, community-dwelling primary care patients. J Am Board Fam Med 2012;25:300-307.

5. Wilkins T, Gillies RA, Harbuck S, Garren J, Looney S, Schade RR. Racial disparities and barriers to colorectal cancer screening in rural areas. J Am Board Fam Med 2012;25:308-317.

6. Haddy RI, Richmond BW, Trapse FM, Fannin KZ, Ramirez JA. Septicemia in patients with AIDS admitted to a university health care system: a case series of 83 patients. J Am Board Fam Med 2012;25:318322.
7. Mao JJ, Leed R, Bowman MA, et al. Acupuncture for hot flashes: decision making by breast cancer survivors. J Am Board Fam Med 2012;25:323-332.

8. Morse DS, Lafleur R, Fogarty CT, Mittal M, Cerulli C. "They told me to leave": how health care providers address intimate partner violence. J Am Board Fam Med 2012;25:333-342.

9. Kemp EC, Floyd MR, McCord-Duncan E, Lang F. Patients prefer the method of "tell back-collaborative inquiry" to assess understanding of medical information. J Am Board Fam Med 2008;21:24-30.

10. John J, Koshy SKG. Current oral antiplatelets: focus update on prasugrel. J Am Board Fam Med 2012;25: 343-349.

11. Sadowsky CH, Galvin JE. Guidelines for the management of cognitive and behavioral problems in dementia. J Am Board Fam Med 2012;25:350-366.

12. Galvin JE, Sadowsky CH. Practical guidelines for the recognition and diagnosis of dementia. J Am Board Fam Med 2012;25:367-382.

13. Lee SH, Cheong YS. Successful endoscopic repair of an iatrogenic colonic perforation during diagnostic colonoscopy. J Am Board Fam Med 2012;25:383-389.

14. Neumann I, Ritter R, Mounsey A. Strongyloides as a cause of fever of unknown origin. J Am Board Fam Med 2012;25:390-393.

15. Evans KL, Brown SR. Many sample closet medications are expired. J Am Board Fam Med 2012;25:394-395.

16. Pavletic A, Hnatiuk O. Puzzling dyspnea caused by respiratory muscle weakness. J Am Board Fam Med 2012;25:396-397. 